\title{
Adapting Grounded Theory in Qualitative Research: Reflections from Personal Experience
}

\author{
Philip Bulawa (Corresponding author) \\ Faculty of Education, University of Botswana \\ P/Bag 0022, Gaborone, Botswana
}

Tel: 267-355-5095. E-mail: bulawap@mopipi.ub.bw

Received: September 25, 2013 Accepted: December 18, 2013 Published: January 16, 2014

doi:10.5296/ire.v2i1.4921

URL: http://dx.doi.org/10.5296/ire.v2i1.4921

\begin{abstract}
Grounded theory is one of the methodologies that have been widely used in qualitative research. However, researchers, especially inexperienced ones have not been sure about its use in the process of the data collection and analysis. The uncertainty arises mainly from the differences that have emerged between Barney G. Glaser and Anselm L. Strauss who previously pioneered grounded theory together. Using the researcher's own PhD study, this paper seeks to show that grounded theory can be adapted to suit studies being undertaken. It demonstrates that there is no one way of undertaking grounded theory studies, and that the initial approach by Glaser and Strauss was never intended to be dogmatic. The paper shows that while there are common elements across most approaches of grounded theory, theorists and users of this approach have applied it differently. Therefore, this suggests that researchers can adopt and adapt the grounded theory approach for their own research.
\end{abstract}

Keywords: category, coding process, elements of grounded theory, grounded theory, methodology, qualitative research

\section{Introduction}

Although grounded theory in research is one of the methodologies that have been widely used in qualitative research, there has been some debate about its use. On the one hand, is the view that grounded theory is a credible methodology researchers should use for qualitative studies. Rennie (1998) argues that the grounded theory approach discovered by Glaser and Strauss in the 1960s is something wonderful in comparison to previously "what was customary research praxis in sociology" (p.114). Rennie (1998) maintains that a significant strength of this approach is that it enables researchers to use data to develop theory rather than to test it. 
Charmaz (2003) also explains that prior to the publication of Discovery by Glaser and Strauss, most qualitative analysis was taught through oral tradition of mentoring. According to Charmaz (2003) this changed with the publication of Discovery which emphasised that qualitative research should move toward theory development. She contends that by publishing Discovery, Glaser and Strauss were providing "a persuasive intellectual rationale for conducting qualitative research that permitted and encouraged novices to pursue it" ( $p$. 253).

On the other hand, a review of the literature shows that there are some areas of weakness researchers would encounter trying to use grounded theory for their studies. Selden (2005) criticises especially Strauss's and Corbin's grounded theory procedures for providing recipes on methodology for inexperienced researchers. Selden (2005) raises concern about the detail to which these steps have been provided which could be interpreted as an attempt at "trying to provide fail-proof measures for thesis making" (p. 120). In his view this could give the impression that if the procedures are not followed as prescribed, then the research may not be robust. Myers (2009) also maintains that while systematic and detailed analysis of data following a given method may be an advantage, it can also be a disadvantage. He argues that first-time users of the grounded theory approach may be overwhelmed by the coding process since "the attention to word and sentence-level coding" (p. 112) may compel them to pay particular attention to a great deal of detail.

Further significant is the debate arising from differences that have emerged between the approaches of Glaser and Strauss, the two pioneers of grounded theory who jointly describe the use of this methodology in qualitative research (Glaser \& Strauss, 1967). With this debate, novice qualitative researchers are often unsure about which version of grounded theory to use.

Against this background, this paper begins by exploring the origins of grounded theory before discussing reasons for the adoption of this methodology and criteria for judging the quality of grounded theory studies. It further provides a critique of this approach which includes the debate about differences that have emerged between Glaser and Strauss. Further discussed is justification for the researcher's decision to adapt grounded theory for the study. Some excerpts of the data from a $\mathrm{PhD}$ study are used as an illustration of the coding process using an adapted grounded theory approach.

\subsection{Purpose of Study}

This paper seeks to demonstrate to the researcher that grounded theory can be adapted in qualitative studies, and that the initial grounded theory approach was a guide for researchers to use in different ways they found suitable.

\subsection{Research Questions}

This paper is guided by three research questions:

1) What perspectives do researchers have about grounded theory? 
2) What are the views of researchers regarding the processes of adapting grounded theory?

3) How have differences between Glaser and Strauss influenced the development and use of grounded theory?

\section{Grounded Theory: Its Origins}

Grounded theory was developed by Glaser and Strauss in the 1960s, when they were working together on a study of staff's handling of dying patients in hospitals (Glaser \& Strauss, 1967). While they were observing the handling of these patients, they recognised the need for a well thought out, clearly formulated methodology and a set of methods for collecting, coding and analysing data that was systematic (Glaser, 1992).

Grounded theory has been used in many disciplines including nursing (Lomborg \& Kirkevold, 2003) and education (Patton, 2002). According to Ary, Jacobs, and Sorensen (2010), the goal of this methodology "is to inductively build a theory about a practice or phenomenon using interviews and observation as the primary data collection tools" (p. 463). Punch (2001) refers to grounded theory as a research strategy aimed at generating theory from data, while Mansourian (2006) describes it as "inductive, contextual and processual" (p. 397). Wiersma and Jurs (2005) emphasise that "if a theory develops based on the data, we have "grounded theory," that is, a theory grounded in the data rather than based on some a priori constructed ideas, notions, or system" (p. 14).

\section{Adopting the Grounded Theory Methodology}

The study adopted grounded theory for various reasons, and one such reason is that this methodology is very relevant to education which "has to do with the identification of research problems from professional practice, and from organisational and institutional contexts" (Punch, 2009, p. 134), situations in which a traditional hypothesis-testing approach would not be appropriate. Punch (2009) maintains that, many problems confronting education research are new since they come from new developments in professional practice or from newly developing contexts. He argues that these areas require empirical research much of which is qualitative, for which theory verification approach would not be appropriate. According to Punch the grounded theory generation approach would be most appropriate for these new areas since there is a lack of grounded concepts that describe and explain what goes on.

Further strength of the grounded theory approach is its focus on inductive strategies of generating theory in contrast to other theoretical perspectives which emphasise theory developed "by logical deduction from a priori assumptions" (Patton, 2002, p. 125). Gay, Mills, and Airasian (2009) point to the analysis of data inductively that is done without making assumptions about the findings prior to collecting evidence.

Grounded theory is further credited for written guidelines for the systematic analysis of the data, complete with clear and specific procedures, and research strategies (Myers, 2009; LaRossa, 2005). As suggested by Thomas and James (2006), although qualitative inquiry is valid, it can be difficult to do. For instance, in education it may involve talking with such 
people as students, parents and teachers, and this way of doing research can lead to a lack of direction in terms of what to do with the data. Therefore, grounded theory is commended for offering a solution by providing a set of procedures and a means by which theory is generated. Thomas and James (2006) argue that with such explicitly laid down procedures, grounded theory has proved to be "an accessible and thoroughly explained method in qualitative inquiry" (p. 768).

Therefore, grounded theory with its guidelines was found more suited for the researcher's study that was based on the research participants' lived experience in secondary schools in Botswana, a topic that had not been studied indepth. The researcher was further attracted to grounded theory because of a framework it offered in terms of the data generation and coding procedures that guide the analytic process which would lead to generating theory (Strauss \& Corbin, 1998).

\section{Adapting Grounded Theory}

Novice qualitative researchers are often unsure of the version of grounded theory to use to undertake their studies. This paper is aimed at helping those who are faced with this dilemma to understand that they can adapt this approach to carry out research. The researcher conducted a qualitative study using a modified version of Strauss's and Corbin's (1990) grounded theory methodology. As indicated by Sarker, Lau, and Sahay (2000), if suitably modified grounded theory can be used in qualitative studies to guide theory development based on the experience of participants about a particular phenomenon.

The literature on research shows that there is no particular way of undertaking grounded theory studies. Glaser and Strauss (1967) state: "Our principal aim is to stimulate other theorists to codify and publish their own methods for generating theory" (p. 8). This suggests that the originators of grounded theory never intended for the process to be prescriptive. LaRossa (2005) also maintains that such comments are an indication that Glaser's and Strauss's initial approach was never intended to be dogmatic. Instead, it was to be a guide for researchers to use grounded theory in different ways they found appropriate. Similarly, Heath and Cowley (2004) indicate that Strauss and Corbin (1998) modified their position in relation to coding and theory construction, maintaining that a rigidly staged process was not their intention.

\section{Criteria for Judging Quality of Grounded Theory Studies}

The literature shows that there are certain criteria one would use to judge the quality of grounded theory studies (Glaser \& Strauss, 1967; Glaser, 1992; Lomborg \& Kirkevold, 2003; Charmaz, 2003; Duchscher \& Morgan, 2004). One such criterion is the continuous process of collecting and analysing data to saturation using the constant comparative method of analysis (Glaser \& Strauss, 1967). The aim of the technique of constant comparative analysis is to force the analyst to be close to the data in order not to come up with subjective understanding of the data (Glaser \& Strauss, 1967; Rennie, 2000). Mansourian (2006) emphasises that the constant comparison process is pivotal for a grounded theory research project to be deemed a success. 
The concepts of fit, work, relevance, and modifiability also describe criteria by which the quality of grounded theory can be judged (Glaser \& Strauss, 1967). The concept of 'fit' means that categories should emerge from the data, and not selected from a theoretical perspective that has been pre-determined. "Work" means that theories should be able to predict, explain, and interpret what is happening in the area of study, while 'relevance' means that theories must be relevant to the action in the area of study it is supposed to explain. "Modifiability" indicates changes grounded theory may have to go through in case new data emerges, "generating qualifications to the theory" (Lomborg \& Kirkevold, 2003, p. 191).

Other important requirements suggested by Glaser (1992, p. 16) as denoting the quality of grounded theory also drew the attention of the researcher. These include the following:

(1) the significance of the researcher getting out into the field to understand what is going on, (2) the importance of theory which is grounded in reality, (3) the nature and significance of experience in the field for the participants and researcher as continually evolving, (4) the active role of persons in shaping the world they live in through the processes of symbolic interaction...

The researcher attempted to undertake his study in accordance with these criteria as much as possible. He carried out two interviews at different times with senior management team members in senior secondary schools in Botswana. This gave the researcher the opportunity to interact with the participants to get an understanding of their expectations of and experience with the implementation of the performance management system. He undertook some preliminary analysis in the field and analysed the data systematically subsequent to the interviews to ensure that the emerging theory was inductively derived from the data (Bulawa, 2011).

\section{Critique of the Grounded Theory Approach}

Although grounded theory has been widely used, there has been some debate about the strengths and weaknesses of this research methodology. This debate has not only emerged between the proponents of Glaser and Strauss versions of grounded theory, but also between the co-founders of grounded theory themselves, as they have had fundamental differences about the use of grounded theory.

\subsection{The Glaser and Strauss Debate}

Glaser and Strauss co-founded grounded theory in the 1960s, and this was followed by the first publication they co-authored titled The discovery of grounded theory: Strategies for qualitative research (Glaser \& Strauss, 1967). Soon after this publication the two scholars then differed on the usage of grounded theory and ceased to publish together on this methodology (Glaser 1978; Strauss, 1987). Jeon (2004) points to their "more independent writing in which their individual views have become more crystallised" (p. 255). This is revealed in Glaser's accusation of Strauss's failure to fully comprehend grounded theory (Glaser, 1978, 1992). Strauss has also expressed concern about Glaser's version of grounded theory for placing too much emphasis on its inductive nature (Mansourian, 2006). 
The views regarding what could have led to differences between Glaser and Strauss after the publication of their work in 1967 have differed. Duchscher and Morgan (2004) argue that their major point of departure is in terms of further development of grounded theory and how it can be used in research. Both Jeon (2004) and Hallberg (2006) are in accord that the profound differences could be in terms of their ontological and epistemological perspectives. On the other hand, Mansourian (2006) is of the view that the disagreements between Glaser and Strauss are not about ontological and epistemological aspects of grounded theory but differences pertaining to procedures which include coding of the data and development of categories.

Another difference between the two concerns verification. Strauss and Corbin (1990) who are for verification argue that grounded theory analysis is more verificational than what Glaser and Strauss had suggested in their original work together. Their perspective on verification is that researchers should continuously examine the data, and should be an on-going process throughout the study. However, Glaser (1992) argues that Strauss's and Corbin's acceptance of verification is indicative of their deviation from doing grounded theory analysis. His perception is that grounded theory is not verificational and that it is only after the development of theory that researchers can verify. Glaser (1978) maintains that, this is a part of the delayed action nature of grounded theory.

Further disagreement between Glaser and Strauss reveals itself in their diverse viewpoints regarding the role that literature should play in a grounded theory study. Glaser (1998) and Glaser and Holton (2007) are against prior review of the literature in the area of study, arguing that it should be read after the theory has been developed from the data. This is in contrast to Strauss and Corbin, who consider the literature as critical from the beginning of the process.

Glaser's (1998) view about the reading of literature beforehand is that this could "contaminate, constrain, inhibit, stifle or...impede the researcher's effort to discover emergent concepts, and hypothesis, properties and theoretical codes from the data that truly fit, are relevant and work" (p. 68). According to Glaser (1998) the basic principle of grounded theory is that the theory should be grounded in the data collected through an inductive process, and that it is therefore, incumbent upon researchers to adopt a neutral position to be able to describe the situation in a non-evaluative way. For Glaser (1998) this should be done to ensure that only the participants' voice is heard. Reading the literature is construed by Glaser as highly likely to blur the researchers' ability to maintain open mindedness to the emergence of a new category that may not have emerged prominently from the data. Glaser's (1992) advice to researchers is that before they proceed to review the literature in the substantive area of study they should ensure that the theory from their own project has been "sufficiently grounded in a core variable and in an emerging integration of categories and properties" (p. 32).

Literature review is from Strauss's and Corbin's (1990) standpoint acceptable. They advocate for both technical and non-technical literature as significant in grounded theory and their contribution to theoretical sensitivity. Technical literature includes "reports of research 
studies, and theoretical or philosophical papers ... [which] can serve as background materials against which one compares findings from actual data gathered in grounded theory studies" (p. 48). Their definition of non-technical literature includes such documents as letters, biographies, diaries, reports, videotapes and other forms of materials.

According to Strauss and Corbin (1990) the reading of literature in grounded theory studies is essential for researchers to identify relevant categories and understand their relationships. Literature can also be used as a way of stimulating theoretical sensitivity "by providing concepts and relationships that are checked out against actual data" (p. 50). Furthermore, Strauss and Corbin argue that it can assist researchers to obtain a range of questions that they would use to ask their respondents, and they can also rely on literature to decide where to go to discover phenomena that is significant to the development of theory. In addition, researchers could use literature to validate the accuracy of their findings, or can rely on literature to show how their findings differ from the published literature.

Other writers of grounded theory side with either Glaser or Strauss. For example, Goulding (1998) is in accord with Glaser that researchers should develop theory first which would then direct them "to the literature which best informs, explains and contextualises the findings" (p. 51). In her view, it is only when there are no longer any new findings emerging from the data that the researcher should begin to review literature and relate the theory from the data to it. Glaser's (1992) perspective that while researchers are advised to continue reading right from the beginning of their study, it should be in areas unrelated to the study is also held by Goulding (1998).

In contrast, there are those who differ with the Glaser argument against reading of literature to prepare for the study. Backman and Kyngäs (1999) for example, describe this argument as unrealistic. They argue that the purpose of reading literature is to clear up the researchers' thoughts and ensure that the topic of study is narrowed down. Similarly, Selden (2005) also stresses the significance of reading literature. This, he argues would avoid repetitive research since there could be other researchers who may have already conducted similar studies on the prospective topic of study, something that could only be revealed through the reading of literature. In this study literature was read in line with Strauss's and Corbin's (1990) viewpoint about its significance in grounded theory and contribution to theoretical sensitivity. As indicated by Selden (2005), the fact that Glaser and Strauss (1967) had advocated for the use of such facilities as libraries, archives and fiction in their earlier work, contradicts Glaser's current perspective about the use of literature.

Glaser and Strauss further differ in the significance they give to the professional and personal experience of researchers, with Glaser (1998) maintaining that the use of such experience would be tantamount to forcing the data when doing grounded theory. He urges researchers to suspend what they already know, and to keep studying the data, conceptualising and constantly comparing. On the contrary, the study gave significance to professional and personal experience of researchers, a perspective held by Strauss and Corbin (1990). They see professional and personal experience as important sources of theoretical sensitivity that 
would help researchers to quickly gain an insight and a better understanding of a phenomenon in comparison to someone who has never had a similar experience.

There are concerns about ambiguities in the different interpretations (Lomborg \& Kirkevold, 2003) of some core terms and concepts in grounded theory. These ambiguities range from differences between Glaser and Strauss in their interpretation of the same concepts to inconsistencies shown by each one of them in labelling or defining the same terms differently. LaRossa (2005) highlights such terms, which include Glaser's (1978) use of the terms variables and categories to mean the same thing; and the different definitions for category used by Glaser and Strauss (1967), Glaser (1992), Strauss (1987), and Strauss and Corbin (1990, 1998). Further highlighted by LaRossa (2005) is the term property which reflects slightly different meanings for both Glaser and Strauss. Another confusion pertains to Strauss's and Corbin's $(1990,1998)$ use of the two concepts of category and subcategory. LaRossa (2005) shows that while to many people a subcategory would denote a category that falls under another category, the way Strauss and Corbin have used it shows that it is not a subcategory under a central category, but a category related to "a focal category" (p. 848). According to LaRossa (2005), these different definitions by both Glaser and Strauss can cause some confusion to users of the grounded theory approach, especially to the novice researchers.

According to McMurray, Pace, and Scott (2004) grounded theory methods generate large amount of data that may be challenging. Such detail in Myers' (2009) viewpoint, might frustrate people in such a way that they may choose a higher level social theory that is already in existence to help explain their findings. Goulding (1998) argues that there could be a danger that researchers may put too much focus on the identification of codes at the expense of the explanation of how they relate to each other.

Although Glaser and Strauss have had fundamental differences in terms of the application of the grounded theory approach and the interpretation of some key concepts, it does not mean that they have differed on everything.

\subsection{Elements of Grounded Theory Common to Glaser and Strauss}

There are some elements of grounded theory in which Glaser and Strauss still agree. These include theoretical sensitivity, theoretical sampling, the coding process, constant comparative analysis, and theoretical memoing which are considered fundamental grounded theory elements that contribute to objectivity (Rennie, 1998).

\subsubsection{Theoretical Sensitivity}

Both Glaser (2004) and Strauss (1987) urge researchers using the grounded theory methodology to be aware of having theoretical sensitivity when they enter the research site. For Corbin and Strauss (2008) sensitivity means having insight, "being tuned in to, being able to pick up on relevant issues, events, and happenings in data" (p. 33). Glaser (2004) explains that theoretical sensitivity requires that researchers enter the research setting with minimal predetermined ideas or prior hypotheses. Glaser (1978) maintains that, researchers have to 
adopt this posture to ensure that they remain sensitive to the data by being able to record events and detect happenings without pre-existing biases.

Two significant researcher characteristics are suggested by Glaser (2004) for developing theoretical sensitivity. First, researchers are obliged to be conscious of the need to maintain analytic distance, as well as tolerate emerging multiple perspectives from the participants, and maintain openness. Second, researchers are required to develop theoretical insights into the area of study and further have the ability to interpret these insights. The researcher's role is to listen to participants expressed views in order to discover their main concerns in the field and how they intend to address such concerns.

According to Strauss and Corbin (1990) theoretical sensitivity is about "having insight, the ability to give meaning to data, the capacity to understand, and capability to separate the pertinent from that which isn't" (p. 41). Unlike Glaser, Strauss and Corbin (1990) argue that theoretical sensitivity is derived from a number of sources. One such source is the reading of literature for researchers to be familiar with publications that would provide them with a rich background of information that would sensitise them to what is happening with the phenomenon of study. Other important sources of sensitivity rejected by Glaser but recognised by Strauss and Corbin (1990) are the professional and personal experience of researchers.

Strauss and Corbin (1990) define professional experience as experience researchers have acquired during years of practice in a particular field. Such experience enables them to understand how things work in that field, why, and what is likely to happen there under certain conditions. Researchers who have had prior personal experience with projects would find this useful during their studies.

For this study the researcher's theoretical sensitivity was derived from a number of sources which included the literature. The researcher's field work was preceded by some extensive reading in such areas as research methodology and performance management systems which was the topic of study. It was vital to be familiar with such literature to have a rich background of information about what was happening with the phenomenon of study. The researcher appreciates the need for researchers to adopt a neutral position during data collection as emphasised by Glaser $(1992,2004)$. However, he disagrees with Glaser's perception that reading of literature beforehand should not be done because it would blur the researcher's ability to maintain open mindedness to the emergence of categories from the data. The researcher concurs with Strauss' and Corbin's (1990) acceptance of reading of literature as an essential way of stimulating theoretical sensitivity "by providing concepts and relationships that are checked out against actual data" (p. 50).

Furthermore, other sources of sensitivity were the researcher's personal and professional experience which he had acquired during years of practice in the field of education as a teacher, a member of the senior management team, and an education officer in the Ministry of Education. Although the researcher considered such experience significant strengths, he also had to be conscious of certain risks. For instance, it was important not just to be aware of prior beliefs but not to allow those beliefs to interfere with the interview process and with the 
data analysis. It was important to be as objective and impartial as possible in the interpretation of events. For instance, at the beginning of the study, the researcher had his own perceptions about senior management teams' possible response to the implementation of the performance management system. These however, were contradicted by what emerged from the data (Bulawa, 2011).

As pointed out by Strauss and Corbin (1998), it was important that the researcher had to maintain an analytic distance by keeping back what he already knew from previous experience to be able to be objective, impartial, and accurate in his interpretation of the data. He had to constantly remind himself of the need to be as open as possible in order not to influence the participants' perceptions but to discover their own beliefs and perspectives.

\subsubsection{Theoretical Sampling}

Another important aspect of the grounded theory methodology is theoretical sampling. It helps researchers to decide the quality of the generated theory (Corbin \& Strauss, 2008; Jeon 2004; Glaser, 1978). Glaser (1978) defines theoretical sampling as "the process of data collection for generating theory whereby the analyst jointly collects, codes, and analyses his data and decides what data to collect next and where to find them, in order to develop his theory as it emerges" (p. 36).

According to Corbin and Strauss (2008) when researchers are doing theoretical sampling they have to take one step at a time beginning with cycles of data gathering and analysis. For Punch (2001) the initial stage is for researchers to collect a small set of data "guided by the initial research questions" (p. 167). This set of data is analysed, before another set of data is collected with the guidance of the emerging directions coming from that initial analysis. This cycle of alternation between data collection and analysis must be continued and stopped only when there is evidence of theoretical saturation. Punch explains that theoretical saturation occurs when additional data can no longer show anything new, but is repeating information that is already in existence.

Corbin and Strauss (2008) stress that in doing theoretical sampling, researchers should ensure that the research is guided by analysis. This process requires researchers "to ask questions and then look to the best source of data to find the answers to the questions" (p. 146). As noted by Jeon (2004), in the process, decisions about such key factors as interview questions, follow-up interviews, and contact with experts in the area of study are made.

Elaborating further on the distinctiveness of the principle of theoretical sampling, Tavakol, Torabi, and Zeialoo (2006) maintain that whereas quantitative inquirers would decide on the size of the sample population before the commencement of the study, the grounded theorists would not. The recruitment of the participants would not be on a representative basis, but on the basis of the expert knowledge they have about the phenomenon under enquiry. That is, the participants are selected on the basis of their experience of the phenomenon under scrutiny.

In this study, the process of theoretical sampling as prescribed in grounded theory was not undertaken to its fullest extent for logistical reasons. All members of the senior management 
team in the senior secondary schools who were available at the time of the field trip were interviewed to ensure that the entire gamut of perspectives available were included. Logistically, these appointments had to be made before the field trip. The time constraint of three weeks in the field for the first round of interview data collection also meant that to jointly collect and analyse data, and ultimately decide which data to collect next and where to find it was not achievable within the timeframe. While some analysis was undertaken in the field and captured in the researcher's field notes, most of the analysis took place after the field trip (Bulawa, 2011).

\subsubsection{The Coding Process}

Both Glaser and Strauss are in agreement regarding the coding as being at the core of their grounded theory approach to doing research. The coding in grounded theory is described by Walker and Myrick (2006) as "the primary intervention into the data" (p. 550). For Jeon (2004), "coding is the defining aspect of analysis within the grounded theory method and is a means by which the quality of emerging theory can be determined" (p. 253).

Furthermore, Strauss and Corbin (1998) define coding as "the analytic processes through which data are fractured, conceptualised, and integrated to form theory" (p. 3). The literature on grounded theory shows that the data have to be analysed and coded to generate categories (Glaser, 1978, 1992; Strauss \& Corbin, 1998). Categories can be described as "a type of concept, usually used for a higher level of abstraction" (Glaser, 1992, p. 38), or as "concepts, derived from data that stand for phenomena" (Strauss \& Corbin, 1998, p. 114). Bryman (2008) defines a category as "a concept that has been elaborated so that it is regarded as representing real-world phenomena” (p. 544)

Two kinds of coding processes namely, substantive coding and theoretical coding are described (Glaser, 1992). According to Glaser (1992) substantive coding is in two levels, open coding and selective coding. In the process of open coding, the aim of the researcher is to generate an emergent set of categories and their properties which should fit, work and are relevant to be integrated into a theory. The researchers have to code for as many categories that might fit; and should ensure that they code different incidences into as many categories as possible. In the process, new categories emerge and new incidences fit existing categories. Glaser (1978) emphasises the need for the researcher to analyse the data line-by-line to be able to identify emerging substantive codes within the data. Further, the researcher should verify and saturate categories, and in the process avoid the risk of missing an important category.

According to Glaser and Holton (2007), one of the rules that govern open coding is to ask questions of the data and the most general question is "What is this data a study of?" Other essential questions include: "What category does this incident indicate?" "What is actually happening in the data?" and "What is the main concern being faced by the participants?" (p. 59). These questions are aimed at provoking researchers to be theoretically sensitive and to be intensive in the process of collecting and coding of data. 
The second stage of Glaser's (1978) substantive coding is selective coding. This stage requires the researcher to selectively code for a core variable. Glaser uses the word variable while Strauss uses category to mean the same thing. This is the stage of coding, where the researcher is required to delimit "coding to only variables that relate to the core variable in sufficiently significant ways to be used in a parsimonious theory" (Glaser, 1978, p. 61). Glaser (1978) suggests that the core variable becomes a guide to further data collection and theoretical sampling.

The purpose of theoretical coding as suggested by Glaser (1978) is to "conceptualise how the substantive codes may relate to each other as hypothesis to be integrated into theory. Theoretical codes are supposed to describe the world theoretically and in so doing give integrative scope, broad pictures and a new perspective" (p. 72). Glaser further explains that theoretical codes can further help analysts to maintain their conceptual level when they write about concepts and how these concepts relate to each other.

Researchers are cautioned by Glaser (1992) that for the grounded theory methodology to be deemed to be authentic, it should explain the prevailing variations in behaviour in the area of study in respect to the main concerns of the participants, and that grounded theory should neither be forced nor derived from concepts which have no relationship to data. In contrast to Glaser's coding process that involves two phases, the coding process by Strauss and Corbin (1990) consists of three phases, of open coding, axial coding, and selective coding.

In the process of open coding, Strauss (1987) also urges researchers to ask questions of the data. He emphasises the significance of generating "questions leading to coding; of line-by-line or paragraph-by-paragraph eliciting categories, and queries about them" (p. 56). According to Strauss and Corbin (1990) open coding is "the part of analysis that pertains specifically to the naming and categorising of phenomena through close examination of data" p. 62).

Although Strauss (1987) and Strauss and Corbin $(1990,1998)$ emphasise line-by-line coding, they maintain that this is not the only way. As revealed by Strauss (1987), open coding is an unrestricted coding of data which is carried out by way of closely scrutinising the fieldnote, interview, or other documents in order "to produce concepts that seem to fit the data" (p. 28). In approaching the process of open coding, a researcher might begin by analysing the first interview with a line-by-line analysis which "involves close examination, phrase by phrase and even sometimes of single words" (Strauss \& Corbin, 1990, p. 72). Alternatively the researcher might code by sentence or paragraph and then decide which name to give the code. Open coding is therefore perceived as an opportunity for researchers to as much as possible uncover, name, and develop concepts. When they undertake this process, they open up the data and as best as possible, explore the thoughts, ideas and meanings that are within the data (Strauss \& Corbin, 1998).

The other significant level of Strauss and Corbin's (1998) method is axial coding, which they define as "the process of relating categories to their subcategories, termed 'axial' because coding occurs around the axis of a category, linking categories at the level of properties and dimensions" (p. 123). The aim of axial coding is to put "the fractured data back together in 
new ways after open coding, by making connections between a category and its subcategories" (Strauss \& Corbin, 1990, p. 96). Researchers are required to take into account three aspects of the phenomenon if these connections are to be achievable. These are the situations in which phenomenon occurs; how people react in such situations; and the consequences of the action taken or inaction (Strauss \& Corbin, 1998). According to Strauss (1987), this should result in cumulative knowledge about relationships between one category and other categories and subcategories. Corbin and Strauss (2008) refer to axial coding as "crosscutting or relating concepts to each other" (p. 195). The aim is to develop what would ultimately be one of several main categories (Strauss \& Corbin, 1990).

The third level of coding is selective coding. This level requires the researcher to know when to cease coding to be able to selectively code for a core category (Strauss, 1987; Strauss \& Corbin, 1998). Jeon (2004) defines the core category as representative of the central problem or issue confronting the participants under study. Once the core category has been discovered, selective coding commences. This leads to further investigation of issues and ideas that are mainly centred round the core category. Strauss (1987) explains that "selective coding pertains to coding systematically and concertedly for the core category" (p. 33).

During this process, the researcher is required to delimit coding to codes that relate to core codes and other categories become subservient to the core category under focus. Strauss and Corbin (1998) point out that at this level of coding, it is essential that categories were finally integrated to form a larger theoretical scheme for the research findings to take the form of theory. With this integration the researcher can decide on the core category that may evolve from a list of categories that represent the main theme of the study. According to Strauss and Corbin (1998) the core category is supposed to have analytic power which gives it the "ability to pull the other categories together to form an explanatory whole" (p. 146).

In the coding process of the data in this study, the researcher adopted the three phase process of open, axial and selective coding recommended by Strauss and Corbin $(1990,1998)$.

\subsubsection{Constant Comparative Method}

It has already been explained that researchers using grounded theory need to maintain a theoretical sensitivity in the process of doing their research. By so doing, the theory generated is grounded in the research data and not from researchers' own preconceived ideas and existing theories. One way of enhancing sensitivity is to employ the constant comparative method to stimulate thought about incidents, concepts, categories and their properties (Glaser, 1978; Strauss \& Corbin, 1998).

Researchers have to compare incidents applicable to each category, and they do that by coding each incident in the data into as many categories of analysis as possible. The basic rule for the constant comparative method is that in the process of coding an incident for a category, it should be compared with previous incidents in the same group as well as different groups that may have been coded in the same category (Glaser \& Strauss, 1967).

A summary of what constant comparison involves is provided by Charmaz (2003, p. 259). She explains: 
Generating codes facilitates making comparisons, a major technique in grounded theory. The constant comparative method of grounded theory means (a) comparing different people (such as their views, situations, actions, accounts, and experiences), (b) comparing data from the same individuals with themselves at different points in time, (c) comparing incident with incident, (d) comparing data with category, and comparing a category with other categories.

It is essential that researchers have to ensure that constant comparison is ongoing, as it is the process by which they sort the emerging themes on account of their similarities and differences (Goulding, 1999). In this study, the views and experiences of different participants, same individuals, incidents and categories were compared during the data analysis.

\subsubsection{Theoretical Memos}

An integral part of the process of generating theory is the writing of theoretical memos. According to Elliott and Lazenbatt (2005) memoing is an essential element of the grounded theory methodology used to control distortion during analysis by sensitising researchers to their personal biases. Memos are defined by Glaser (1978) as "the theorising write-up of ideas about codes and their relationships as they strike the analyst while coding" (p. 83). Strauss (1987) describes theoretical memos as "writing in which the researcher puts down theoretical questions, hypothesis, summary of codes, etc - a method of keeping track of coding results and stimulating further coding, and also a major means for integrating the theory" (p. 22).

Memoing is an element that Glaser (1978) considers a continuous process which begins with the first coding of data through to sorting and writing papers to the end of the study. Memos can be of any length, ranging from just a sentence, a paragraph, or through to a few pages. They record ideas in any form of language, formal or informal, as at this stage the major concern is ideas.

According to Strauss and Corbin (1990) researchers have to develop their own style of memoing, which may include the use of software, colour coded cards, and putting type-written pages into folders or notebooks. Of most importance is for researchers to ensure that their memos are orderly, systematic, and can be easily retrievable for purposes of sorting or cross-referencing. Strauss and Corbin (1990) emphasise the importance of dating each memo and referencing the source from which it was taken.

In this study, the researcher created a column which he labelled "comments/memo" on the main Microsoft Excel spreadsheet. The column recorded early coding to write his ideas about the codes and their relationship to each other. Later memos were recorded on the mind maps that were constructed as well as in the research diary. Memos were of assistance to the researcher when he connected categories with each other and with their subcategories. The process of memoing which started with the first coding of the data, continued to the end of the analysis (Bulawa, 2011). 


\section{Illustration of the Coding Process Using Adapted Grounded Theory}

This section describes the grounded theory coding process in a study titled: Implementation of the Performance Management System in Senior Secondary Schools: The Perspective of the Senior Management Team (Bulawa, 2011, 2013). The coding process used in this study is guided by Strauss's and Corbin's (1998) three stage process of open coding, axial coding, and selective coding described earlier.

While the order of the coding processes as described by Bulawa $(2011,2013)$, are in that order, they are not entirely sequential. For example, in doing the axial coding that constitutes the second phase of the process, the coding that had been done in the first stage was revised on several occasions. The coding of data mainly focused on the interview transcripts, but was complemented by the field notes taken during the field trip. During the analysis of the data, the notes were checked against the recorded interviews and against the codes generated.

The first stage of the coding, comprised several iterations and several revisions, and was recorded in a Microsoft Excel spreadsheet which was useful in different ways. For instance, it was relatively easy to modify codes, and introduce new coding at different times during the process. It was also easy to recode data, code data with multiple codes, and sort the spreadsheet by codes or participants. The coding began with one whole transcript at a time coding phrase by phrase or sentence by sentence (Strauss \& Corbin, 1998; Strauss, 1987), depending on the content. Table 1 is an extract from one of the later spreadsheets in which the open coding was recorded. The table consisted of more columns than those reproduced here. The second column, in particular, was the synthesis of several other columns. Table 1 comprises four columns called identifier, code, text, and comments or memos (Bulawa, 2011).

The first column labelled "Identifier" identifies the interview data in the third column by participant name and by the position the text held in the interview transcript. The three letters of the code identify the participant and the three digits identify the location of the text in the transcript. After the spreadsheet had been sorted in various ways, these codes also allowed the spreadsheet to be restored to its original form that is, with the text pieces in the third column appearing in the same order as they did in the interview transcript.

The second column called "Code" recorded how the text in the third column was coded. Table 1 shows that the code consists of up to three parts. The first part or stem is the broader idea in which a family of codes that describe different incidents of that stem are nested. "For example in the first row, the text 'We expect PMS to make some focus on the classroom situation, the educational context' was coded against Factor needed for implementation to be successful: contextualise: classroom focus" (Bulawa, 2011, p. 117; Bulawa, 2013, p. 61). In most cases, the data was first coded by the smallest unit or micro-unit, in this case, "classroom focus". As the data coding progressed from one transcript to the next, it became clear that these "microcodes" clustered into broader codes which eventually further aggregated into the stems that appear at the beginning of each complete code. While some of the words or phrases used in the codes of the open coding process are those of the researcher, many of them also come from the participants and are thus 'in-vivo' codes (Bulawa, 2013). 
Reflected in the third column is the text from the transcripts which was 'fragmented' for coding. While almost all the text in each transcript was coded, some text was uncoded because it was found totally irrelevant to the topic such as talk about the weather or school events and activities that had no relationship to the PMS. The fourth column 'comment/memo' is a record of the researcher's reflections of the data. As ideas emerged from the data, the researcher paused and wrote a memo to himself regarding the codes (Bulawa, 2011, 2013).

Table 1. Extract of the open coding spreadsheet

\begin{tabular}{|c|c|c|c|}
\hline Identifier & Code & Text & Comment/memos \\
\hline BВA039 & $\begin{array}{l}\text { Factor needed for } \\
\text { implementation to be } \\
\text { successful: } \\
\text { contextualise: } \\
\text { classroom focus }\end{array}$ & $\begin{array}{l}127-128 \text { We expect PMS to make } \\
\text { some focus on the classroom } \\
\text { situation, the educational context. }\end{array}$ & $\begin{array}{l}\text { Teaching and } \\
\text { learning } \\
\text { considered core } \\
\text { business of the } \\
\text { schools }\end{array}$ \\
\hline BВB099 & $\begin{array}{l}\text { Factor needed for } \\
\text { implementation to be } \\
\text { successful: assessment: } \\
\text { simplify mathematical } \\
\text { calculations }\end{array}$ & $\begin{array}{l}366-367 \text { The mathematics should be } \\
\text { made less complex. Because some } \\
\text { people are humanities oriented. I am } \\
\text { talking about calculation to a specific } \\
\text { point. }\end{array}$ & $\begin{array}{l}\text { Simplify PMS } \\
\text { math calculations } \\
\text { for paperwork } \\
\text { user-friendly }\end{array}$ \\
\hline MMA068a & $\begin{array}{l}\text { Factor needed for } \\
\text { implementation to be } \\
\text { successful: } \\
\text { contextualise: focus on } \\
\text { core business }\end{array}$ & $\begin{array}{l}252-254 \text { Because of the paper work it } \\
\text { brings, the meetings, people feel } \\
\text { those can still be left out and focus on } \\
\text { our core business which is to provide } \\
\text { quality education. }\end{array}$ & $\begin{array}{l}\text { Perception that } \\
\text { PMS should } \\
\text { focus on the } \\
\text { provision of } \\
\text { education; and } \\
\text { not paper work } \\
\text { and meetings. }\end{array}$ \\
\hline PPA035 & $\begin{array}{l}\text { Factor needed for } \\
\text { implementation to be } \\
\text { successful: } \\
\text { head's school } \\
\text { empowerment } \\
\text { school heads to take } \\
\begin{array}{l}\text { decisions about PMS } \\
\text { based on unique needs } \\
\text { of their schools }\end{array} \\
\end{array}$ & $\begin{array}{l}240-243 \text { But if you look at our } \\
\text { different environments and needs as } \\
\text { schools, or if this school has to be } \\
\text { unique, I must as its school head have } \\
\text { certain powers in order to change } \\
\text { certain things about the reform. }\end{array}$ & $\begin{array}{l}\text { Empowerment of } \\
\text { school heads to } \\
\text { taker certain } \\
\text { decisions about } \\
\text { PMS? Which } \\
\text { decisions? }\end{array}$ \\
\hline LLB040 & $\begin{array}{l}\text { Reasons for PMS not } \\
\text { working well: cascade: } \\
\text { information distortion } \\
\text { as it is relayed from } \\
\text { one person to another }\end{array}$ & $\begin{array}{l}\text { 144-146 Yes it becomes distorted as } \\
\text { information goes from one person to } \\
\text { another and at the end of the day you } \\
\text { find that you have lost so many issues } \\
\text { that you could have discussed. }\end{array}$ & $\begin{array}{l}\text { Limitation of } \\
\text { cascade approach } \\
\text { to training } \\
\text { delivery- } \\
\text { information } \\
\text { distortion } \\
\end{array}$ \\
\hline PPA020 & $\begin{array}{l}\text { Reasons for PMS not } \\
\text { working well: cascade: } \\
\text { lack of openness for } \\
\text { other ideas }\end{array}$ & $\begin{array}{l}\text { 114-117 Another thing that I have } \\
\text { noted in the past was this that even } \\
\text { the people that were cascading it } \\
\text { were up-tight, very, very tight. They } \\
\text { did not even leave room that some of } \\
\text { us who are receiving the information } \\
\text { could also be looking at the system } \\
\text { differently. }\end{array}$ & $\begin{array}{l}\text { Top-down } \\
\text { approach to } \\
\text { information } \\
\text { dissemination - } \\
\text { lack of openness } \\
\text { for } \\
\text { implementers' } \\
\text { ideas by trainers }\end{array}$ \\
\hline
\end{tabular}

Table from Thesis submitted for the degree of Doctor of Philosophy (Bulawa 2011, p. 119). 
During the open coding, it became evident that there were some issues in the data that were not clearly explained in the first interview. These were noted in the spreadsheet and the researcher followed them up in the second round of interviews. The relevant parts from the transcription of the second interviews were pasted into the spreadsheet as illustrated in Table 2.

Table 2. Extract from spreadsheet illustrating inclusion of data from the second interview

\begin{tabular}{|c|c|c|c|c|}
\hline Order & Code & Text & Comment/memos & $\begin{array}{l}\text { Missing info/clarification } \\
\text { (interview two) }\end{array}$ \\
\hline AAA008 & $\begin{array}{l}\text { Outcomes of the } \\
\text { PMS: PMS: } \\
\text { assessment of } \\
\text { individual } \\
\text { performance }\end{array}$ & $\begin{array}{l}37-42 \text { And then } \\
\text { there is also what } \\
\text { is called a } \\
\text { performance plan; } \\
\text { a development } \\
\text { plan. } \\
\text { development plan } \\
\text { is where you } \\
\text { identify areas } \\
\text { where you feel } \\
\text { you need to be } \\
\text { developed as an } \\
\text { individual, say I } \\
\text { could identify } \\
\text { human resource } \\
\text { management as an } \\
\text { area where I feel I } \\
\text { should be } \\
\text { developed. }\end{array}$ & $\begin{array}{l}\text { Performance } \\
\text { development } \\
\text { plan seems to } \\
\text { crosscut } \\
\text { interviews, so } \\
\text { there is need for } \\
\text { more } \\
\text { explanation. }\end{array}$ & $\begin{array}{l}\text { I: Tell me about the PDPs. What } \\
\text { are they? SH: It is a performance } \\
\text { development plan; a plan which } \\
\text { has aspects of individuals' } \\
\text { performance, how the individual } \\
\text { is performing with regard to } \\
\text { certain objectives. And then the } \\
\text { development part is for the } \\
\text { development of an individual. } \\
\text { You identify your needs as an } \\
\text { individual and then you say to } \\
\text { your supervisor, I need to be } \\
\text { developed on this whether it is } \\
\text { ICT and so on. }\end{array}$ \\
\hline LLA043 & $\begin{array}{l}\text { Role of teachers } \\
\text { in the } \\
\text { implementation } \\
\text { process: } \\
\text { implementer: } \\
\text { initiate } \\
\text { activities }\end{array}$ & $\begin{array}{l}154 \text { They are } \\
\text { initiative owners. } \\
\text { LLA001 }\end{array}$ & $\begin{array}{l}\text { This keeps } \\
\text { recurring and } \\
\text { seems to suggest } \\
\text { a major role. } \\
\text { Find out what it } \\
\text { means to be an } \\
\text { initiative owner. }\end{array}$ & $\begin{array}{l}\text { I: You mentioned that teachers } \\
\text { are initiative owners. What does } \\
\text { this really mean? SH: They are } \\
\text { action players, those who do. I: } \\
\text { These are initiative owners. SH: } \\
\text { Yes. I: Give me an example. SH: } \\
\text { Eh, let me take an example of } \\
\text { customer standards, the person } \\
\text { who would have taken this } \\
\text { initiative should come up with } \\
\text { ways of measuring the standards, } \\
\text { what is that we are going to do to } \\
\text { make sure that our customers are } \\
\text { okay? Those who would be saying } \\
\text { within three days we would have } \\
\text { paid our suppliers or you can only } \\
\text { wait for } 30 \text { minutes before you } \\
\text { could get help. Those are the } \\
\text { action doers. I: So those are the } \\
\text { initiative owners. SH: Yes. }\end{array}$ \\
\hline
\end{tabular}

Table from Thesis submitted for the degree of Doctor of Philosophy (Bulawa 2011, p. 120). 
The process of clustering of codes that the researcher undertook right from the beginning of open coding resulted in the emergence of the stems. As a guide to this process of clustering, he asked and answered questions such as, "What does this coded incident represent in the data?" This process resulted in many changes with some stems being dropped since they were found to be unsuitable while others were re-worded. What also changed was the clustering of codes, as some of the codes were found to be more relevant nested in one stem and not in the other. This continuous process which was carried out until the coding process was completed.

The repeated coding and comparison of codes was also vital because the process had generated thousands of codes many of which were similar or the same. This situation required the researcher to distinguish as early as possible in the analytic process what Corbin and Strauss (2008) call "lower-level explanatory concepts from the larger ideas or higher-level concepts that seem to unite them" (p. 165). Such differentiation at an early stage of analysis was imperative to avoid the risk of ending up with many pages of concepts that would have made it difficult for the researcher to fit them. The researcher had to elevate the "higher-level concepts" to the level of topic headings. These headings represented broader ideas, as they also seemed to permeate interviews.

On the other hand, the 'lower-level concepts' seemed to explain something about the 'higher-level concepts'. Some examples of the initial high-level concepts included measuring and monitoring and training. There were lower-level concepts that explained something about measuring and monitoring. These include lesson observation, checking teachers record of work, assessing performances and checkpoints reviews. Those that explained training were such lower-level concepts used by the participants as work shopping, resourcing, coaching, in-servicing, cascading and staff development. For instance, some participants explained that the PMS promoted regular lesson observation checking of teachers' record of work by supervisors as means by which they measured and monitored the performance of teachers in the classroom. Participants also used such concepts as work shopping and resourcing to illustrate the role of the senior management team of providing training to their staff about the PMS. This was a coding process that produced thousands of codes.

At the end of this process hundreds of conceptual labels or codes remained which still had to be reduced by identifying particular phenomena in the data and group the concepts around them in a process called categorising (Strauss \& Corbin, 1990; Strauss, 1987). To further identify codes that were repeated and to decide whether or not some of those which were similar or the same could be integrated, or deleted, a list of all the codes in the Microsoft excel data was transferred to a spreadsheet according to their stems. This process revealed that even some of the stems of the codes had a lot in common with each other. Where such commonalities were found to exist, these were either merged with others or were deleted.

For instance, there were 102 codes under the stem Attributes needed to make PMS a goer which were found to permeate most of the other codes under different stems. These were therefore either integrated or deleted because they provided no new information in the data, and this also meant that the stem itself ceased to exist. This also applied to codes under stems Deputy opinion about PMS, HOH opinion about PMS and SH opinion about PMS and the 
stems themselves which also ceased to exist. They were merged with codes under the stems Deputy understanding of the purpose of PMS, HOH understanding of the purpose of PMS and SH understanding of the purpose of PMS since they were either similar or were exactly the same. For example, the participants' "opinion about PMS" and "understanding of the purpose of PMS" reflected similar or the same responses. For instance, their response of The PMS was introduced to improve performance and productivity was nested in both stems. Another example pertains to the initial codes under the separate stem of Evidence of PMS not working well which were also integrated into codes under the stem Reasons for PMS not working well since they were also found to be either similar or the same to be treated as separate. This process of integration reduced the stems from twenty to thirteen while the conceptual labels or codes themselves were reduced from a total of well over eight hundred to just above four hundred. Table 3 shows a list of the final stems of the codes following the process of integration (Bulawa, 2011).

Table 3. Integration of stems and codes

\begin{tabular}{ll}
\hline Stems of the Codes & $\begin{array}{l}\text { Number } \\
\text { references }\end{array}$ \\
\hline Change required & 22 \\
\hline Deputy understanding of the purpose of PMS & 23 \\
\hline Factor needed for implementation to be successful & 218 \\
\hline HOH understanding of the purpose of PMS & 18 \\
\hline Outcomes of the PMS & 128 \\
\hline Reasons for PMS not working well & 355 \\
\hline Role of deputy in the implementation process & 23 \\
\hline Role of HOH in the implementation process & 27 \\
\hline Role of Ministry in the implementation process & 17 \\
\hline Role of SH in the implementation process & 41 \\
\hline SH understanding of the purpose of PMS & 52 \\
\hline Steps in the implementation process & 55 \\
\hline Things that are working about PMS & 156 \\
\hline
\end{tabular}

Table from Thesis submitted for the degree of Doctor of Philosophy (Bulawa 2011, p. 123).

The process of integration of the stems and their codes made it easier to identify categories and their relationship to concepts. The next level of the data analysis was therefore to code at a higher level for the main category using mind maps in a process called axial coding (see Appendix for an example of a mind map used).

In axial coding the researcher had put back the same data that he had previously fractured during the process of the open coding "in new ways by making connections between a category and its subcategories" (Strauss \& Corbin, 1990, p. 97). As illustrated in the appendix, the researcher undertook this task with the help of mind maps to analyse each of the thirteen stems and all the categories and codes under each one of them. The use of the mind map was 
a strategy to organise thoughts and, be able to make a link between categories to determine which ones became the main categories or subcategories. This mind map shows that improve performance emerged as the main category with improve personal practice and accountability as examples of subcategories while others such as measuring and monitoring became concepts that explain both the main category and its subcategories. Note that at some stage during open coding, concepts such as measuring and monitoring were categories in their own right. Nonetheless with further clustering and analysis other codes became broader ideas and superseded them to become categories because they had more analytic power.

This process was significant to the researcher as he was looking "for answers to questions such as why and how come, where, when, how, and with what result?" (Strauss \& Corbin, 1998, p. 127). Guided by these questions, the different categories and the concepts, the researcher identified in the last stage of the process of open coding produced five main categories. The process of axial coding was followed by selective coding which was the third stage of the data analysis for the central-category to ultimately develop theory.

The selective coding is a process that requires the major categories to be finally integrated to form a larger theoretical scheme for the research findings to take the form of theory. The integration is essential for the researcher to decide on a central category also called core-category. The central category represents the main theme of the study and may evolve from a list of existing categories. It should be an abstraction and analysed in a few condensed words that seem to provide an explanation about what the research is all about (Strauss \& Corbin, 1998). The central category should have analytic power which gives it the "ability to pull the other categories together to form an explanatory whole" (Strauss \& Corbin, 1998, p. 146). Or as Goulding (2002) points out, the central category has a theoretical significance and therefore its development should be traced back to the data. It must pull "together all the strands in order to offer an explanation of the behaviour under study" (p. 88). In this study, the process was aided by diagrammatic representations that visually captured the synthesis process that the researcher was undergoing. The process was repeated several times until the central category developed satisfactorily pulled together the categories from the axial coding.

During the entire coding process, the researcher used constant comparison as described earlier in this paper. The aim was to stimulate thought about incidents, concepts, categories, and theory development. For instance, in the open coding phase, the many codes that were generated were constantly compared to ensure that those which were similar or were the same were not repeated since they provided the same information and nothing new about the phenomenon of study. It was further significant to constantly make comparison to distinguish between what Corbin and Strauss (2008) call "lower-level explanatory concepts from the larger ideas or higher-level concepts" (p. 165).

The constant comparative method also employed to move up to the axial and selective coding levels of the process. In axial coding, the researcher had to identify the main categories from a range of categories that had emerged at the end of open coding. This process involved making connections between the different categories to determine those that represented 
broader ideas. These were elevated to the level of the main categories, while the rest were converted into subcategories that explained the main categories.

A similar process of constant comparison applied to the selective coding. In this process the researcher had to delimit theory by reducing the original list of categories to one central category which represented the major explanatory idea coming out of the data. Deciding on the central category involved a comparison of all the main categories to establish their relationship in order to be able to decide on the main idea and ultimately write theory. At this level the researcher was not only in possession of the coded data but also some memos to compare and start writing theory. In summary grounded theory as originally conceived by Glaser and Strauss (1967) is a methodology of iterations called the process of constant comparison which requires researchers to move back and fourth among the data right from coding for concepts through to categories and theory development.

\section{Limitations}

Adapting grounded theory in this study became a major challenge since there is no consensus about its application in qualitative research. Barney Glaser's and Anselm Strauss's divergent views over the usage of grounded theory in qualitative studies, have not only attracted debate between the two pioneers of the approach, but also amongst scholars in support of either of these perspectives. Furthermore, other scholars argue that researchers are free to use any version of grounded theory, and that they are also at liberty to adapt this approach provided they are within certain common general procedures. Confronted with this debate, the dilemma for inexperienced researchers in particular, is deciding which one of the grounded theory versions to apply in qualitative research.

\section{Conclusion}

This paper has illustrated that there is no one way of undertaking a grounded theory study. The review of the literature shows that although initially Glaser and Strauss had developed grounded theory together, they later differed in terms of its application. In addition to their different perspectives of this approach, other versions of grounded theory such as that developed by Charmaz also emerged. Therefore, such divergence is an indication that researchers can use not only any other version of the grounded theory approach of their choice, but that they can also adapt it in a manner that suits their own studies.

Further revealed in the paper is that, whatever version researchers adopt for their studies, there are common elements that should be adhered to by those using grounded theory. Such elements include theoretical sensitivity, theoretical sampling, constant comparative method, and theoretical memos. Consequently, researchers who choose to adapt the grounded theory approach, should ensure they take into account these elements for their studies to be deemed credible. As reflected in the literature, these elements could to a large extent, contribute to grounded theory as an approach that represents a coordinated and systematic overall research strategy that is flexible, in comparison to other approaches which sometimes lack well-formulated methods for the analysis of data. 


\section{References}

Backman, K., \& Kyngäs, H. A. (1999). Challenges of the grounded theory approach to a novice researcher. Nursing and Health Sciences, 1, 147-153. http://dx.doi.org/10.1046/j.1442-2018.1999.00019.x

Bryman, A. (2008). Social research methods (3rd ed.). Toronto: Oxford University.

Bulawa, P. (2011). Implementation of the Performance Management System in Senior Secondary Schools: The Perspective of the Senior Management Team. PhD thesis. Townsville: James Cook University.

Bulawa, P. (2013). Constraints to Senior Management's Capacity to Implement the Performance Management System I Senior Secondary Schools in Botswana. International Education Studies, 6(5), 56-67. http://dx.doi.org/10.5539/ies.v6n5p56

Charmaz, K. (2003). Grounded Theory: Objectivist and Constructivist Methods. In N. K. Denzin \& Y. S. Lincoln (Eds.), Strategies of qualitative inquiry (pp. 249-291). Thousand Oaks, CA: Sage Publications.

Corbin, J., \& Strauss, A. (2008). Basics of qualitative research: Techniques and procedures for developing grounded theory. Thousand Oaks, CA: Sage Publications.

Duchscher, J. E. B., \& Morgan, D. (2004). Grounded theory: Reflections on the emergence vs. forcing debate. Journal of Advanced Nursing, 48(6), 605-612. http://dx.doi.org/10.1111/j.1365-2648.2004.03249.x

Elliott, N., \& Lazenbatt, A. (2005). How to recognise a "quality" grounded theory research study. Australian Journal of Advanced Nursing, 22(3), 48-52.

Gay, L. R., Mills, G. E., \& Airasian, P. (2009). Educational research: Competencies for analysis and applications. London: Pearson.

Glaser, B. G. (1978). Advances in the methodology of grounded theory: Theoretical sensitivity. Mill Valley: The Sociology Press.

Glaser, B. G. (1992). Emergence vs forcing: Basics of grounded theory analysis. Mill Valley: The Sociology Press.

Glaser, B. G. (1998). Doing grounded theory: Issues and discussions. Mill Valley: The Sociology Press.

Glaser, B. G. (2004). Naturalist Inquiry and Grounded Theory. Forum Qualitative Sozialforschung / Forum: Qualitative Social Research, 5(17), 1-19.

Glaser, B. G., \& Holton J. (2007). Remodeling grounded theory. Historical Social Research, Supplement, 19, 47-68.

Goulding, C. (1998). Grounded theory: The missing methodology on the interpretivist agenda. Qualitative Market Research: An International Journal, 1(1), 50-57. http://dx.doi.org/10.1108/13522759810197587 
Goulding, C. (1999). Grounded theory: Some reflections on paradigm, procedures and misconceptions. University of Wolverhampton Business School Working Paper Series.

Goulding, C. (2002). Grounded theory: A practical guide for management, business and market researchers. London: Sage Publications.

Hallberg, L. R. M. (2006). The "core category" of grounded theory: Making constant comparisons. International Journal of Qualitative Studies on Health and Well-being, 1 , 141-148. http://dx.doi.org/10.1080/17482620600858399

Heath, H., \& Cowley, S. (2004). Developing a grounded theory approach: a comparison of Glaser and Strauss. International Journal of Nursing Studies, 41, 141-150. http://dx.doi.org/10.1016/S0020-7489(03)00113-5

Jeon, Y. H. (2004). The application of grounded theory and symbolic interactionism. Scandinavian Journal of Caring Sciences, 18(3), 249-256. http://dx.doi.org/10.1111/j.1471-6712.2004.00287.x

LaRossa, R. (2005). Grounded theory methods and qualitative family research. Journal of Marriage and Family, 67, 837-857. http://dx.doi.org/10.1111/j.1741-3737.2005.00179.x

Lomborg, K., \& Kirkevold, M. (2003). Truth and validity in grounded theory - a reconsidered realist interpretation of the criteria: Fit, work, relevance and modifiability. Nursing Philosophy, 4,189-200. http://dx.doi.org/10.1046/j.1466-769X.2003.00139.x

Mansourian, Y. (2006). Adoption of grounded theory in LIS research. New Library World, 107(9/10), 386-402. http://dx.doi.org/10.1108/03074800610702589

McMurray, A. J., Pace, R. W., \& Scott, D. (2004). Research: A commonsense approach. Southbank, Victoria: Thomson Social Science Press.

Miller, S. I., \& Fredericks, M. (1999). How does grounded theory explain? Qualitative Health Research, 9(4), 538-551. http://dx.doi.org/10.1177/104973299129122054

Myers, M. D. (2009). Qualitative research in business \& management. London: Sage Publications.

Patton, M. Q. (2002). Qualitative research \& evaluation methods. Thousand Oaks, CA: Sage Publications.

Punch, K. F. (2001). Introduction to social research: Quantitative and qualitative approaches. London: Sage Publications.

Punch, K. F. (2009). Introduction to research methods in education. London: Sage Publications.

Rennie, D. L. (1998). Grounded theory methodology: The pressing need for a coherent logic of justification. Theory \& Psychology, 8(1), 101-119. http://dx.doi.org/10.1177/0959354398081006 
Rennie, D, L. (2000). Grounded theory methodology as methodical hermeneutics: Reconciling realism and relativism. Theory \& Psychology, 10(4), 481-502. http://dx.doi.org/10.1177/0959354300104003

Sarker, S., Lau, F., \& Sahay, S. (2000). Building an Inductive Theory of Collaboration in Virtual Teams: An Adapted Grounded Theory Approach. Proceedings of the $33^{\text {rd }}$ Hawaii International Conference on System Sciences. http://dx.doi.org/10.1109/HICSS.2000.926934

Selden, L. (2005). On grounded theory - with some malice. Journal of Documentation, 61(1), 114-129. http://dx.doi.org/10.1108/00220410510578041

Strauss, A., \& Corbin, J. (1990). Basics of qualitative research: Grounded theory procedures and techniques. Thousand Oaks, CA: Sage Publications.

Strauss, A., \& Corbin, J. (1998). Basics of qualitative research: Techniques and procedures for developing grounded theory. Thousand Oaks, CA: Sage Publications.

Strauss, A, L. (1987). Qualitative analysis for social sciences. Cambridge: Cambridge University Press. http://dx.doi.org/10.1017/CBO9780511557842

Tavakol, M., Torabi, S., \& Zeialoo, A. A. (2006). Making sense of grounded theory approach: Implications for medical education research. Journal of Medical Education, 9(1), 17-24.

Thomas, G., \& James, D. (2006). Reinventing grounded theory: Some questions about theory, ground and discovery. British Educational Research Journal, 32(6), 767-795. http://dx.doi.org/10.1080/01411920600989412

Walker, D., \& Myrick, F. (2006). Grounded theory: An exploration of process and procedure. Qualitative Health Research, 16(4), 547-559. http://dx.doi.org/10.1177/1049732305285972

Wiersma, W., \& Jurs, S. G. (2005). Research Methods in Education: An Introduction. Boston: Pearson Education, Inc.

\section{Copyright Disclaimer}

Copyright reserved by the authors.

This article is an open-access article distributed under the terms and conditions of the Creative Commons Attribution license (http://creativecommons.org/licenses/by/3.0/). 